\title{
How Birds Survived the Cretaceous Mass Extinction: Secret Hidden within Their Tiny Teeth
}

I $\mathrm{n}$ the Cretaceous mass extinction 65 million years ago, evergreen plants started to decline and died out in the darkness due to asteroid collision and extensive volcanic activities, as suggested in some hypothetical episodes.

This great catastrophic event might have further led to the extinction of plant-eating dinosaurs, and eventually become a complete disaster for all non-avian dinosaurs. The only dinosaur lineage that survived this extinction event was the ancestors of all extant birds.

Why only one lineage of dinosaurs survived the extinction has been a mystery for a long time. A research team led by associate Prof. LI Zhiheng from the Institute of Vertebrate Paleontology and Paleoanthropology (IVPP) of the Chinese Academy of Sciences and his collaborators found clues about dietary differences between bird and non-avian dinosaurs from the nuances of their teeth, which helped unveil the mystery.

The study was published in BMC Evolutionary Biology on April 21.

The researchers explored the detail tooth microstructure within early Cretaceous birds and made a further close comparison with their closest dinosaur relatives, like Microraptor and Anchiornis.

In the previous study, the researchers found that there was a particular dentin layer (called porous mantle dentin) directly beneath enamel in carnivorous dinosaurs through the application of Transmission X-ray Microscopy (TXM) on fossil teeth. This particular

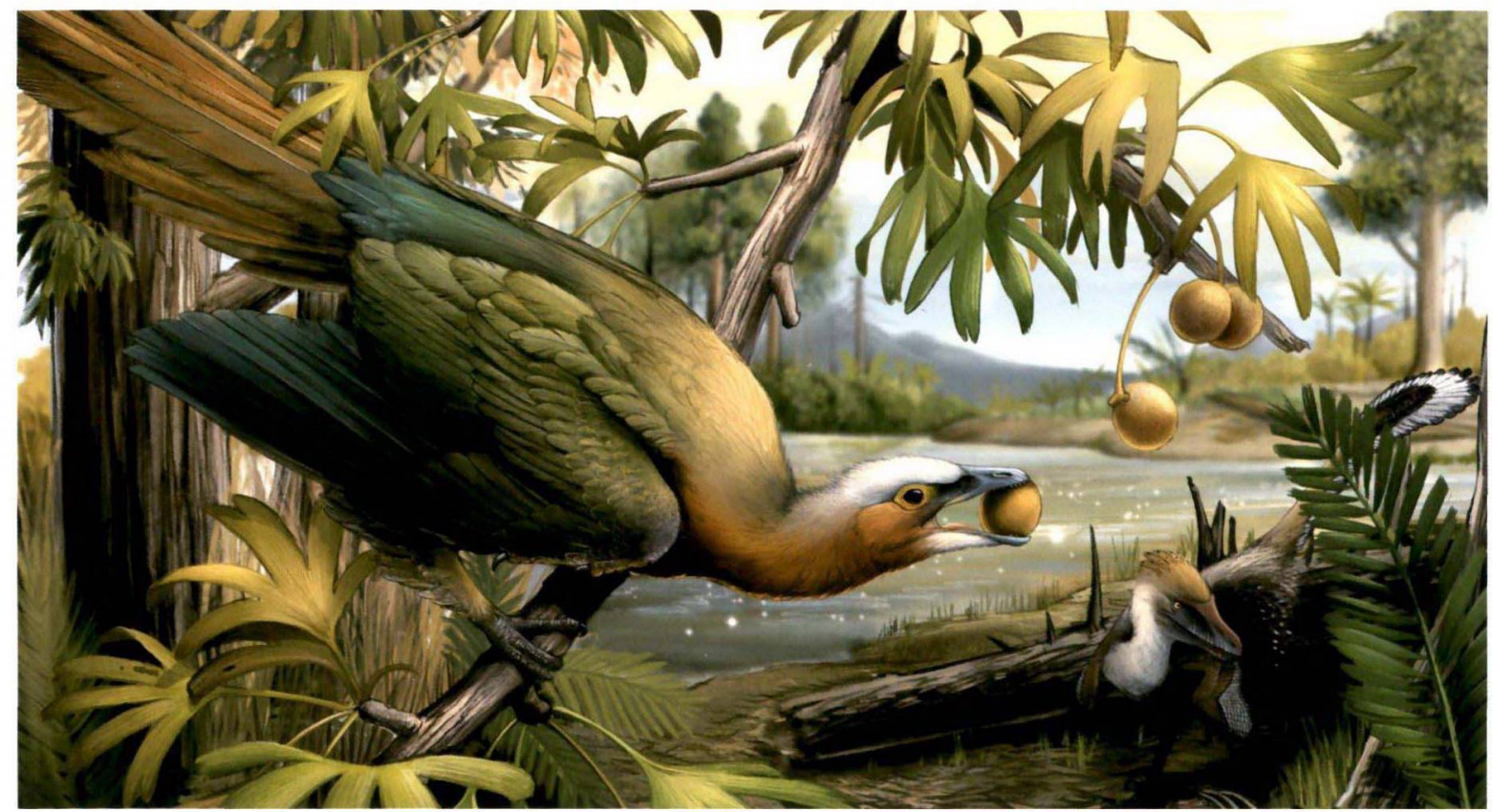

Ecological reconstruction of a seed-eating bird (left), which shared the same wood forest with a non-avian theropod dinosaur (right), The scenario shows early birds evolved different dietary preferences (herbivorous or omnivorous) than those of predators and avoided direct competition. 


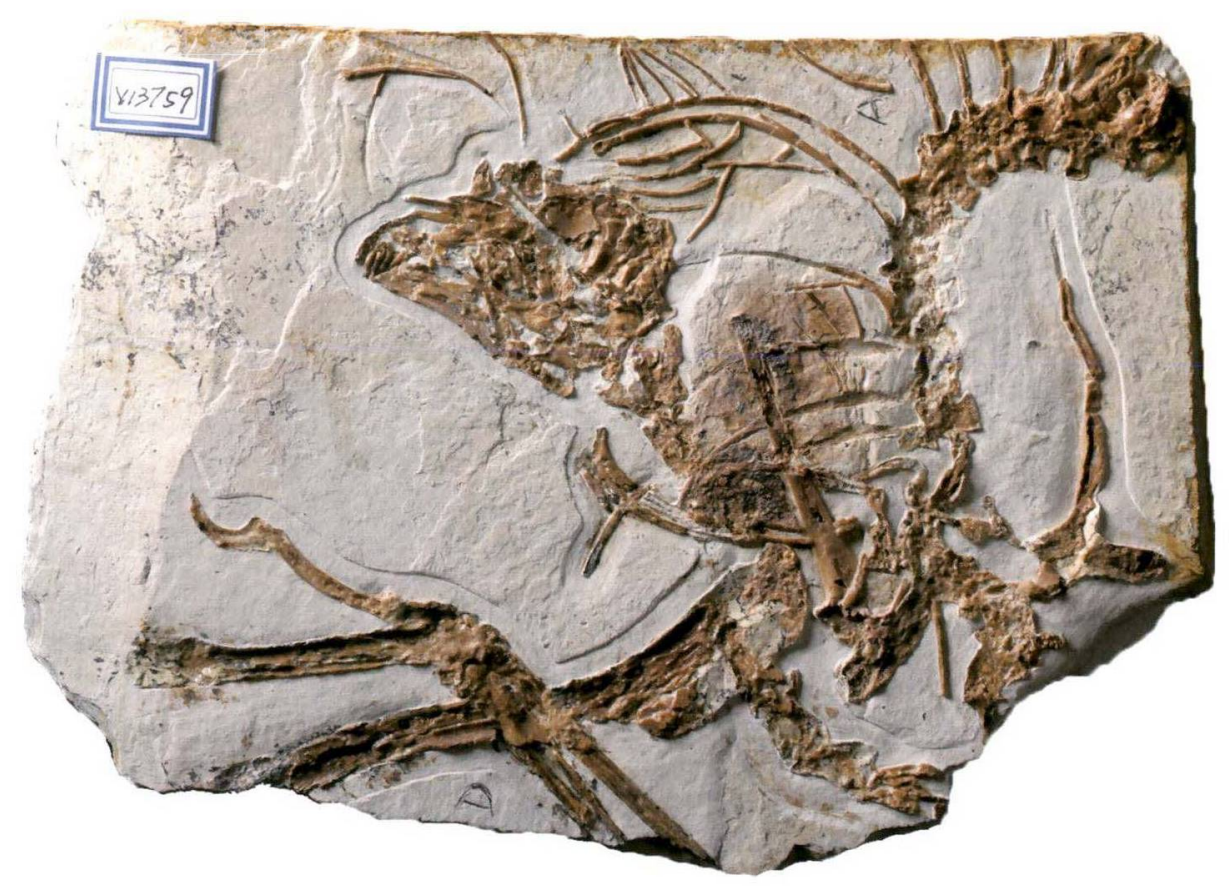

dentine served as a key cushion in reducing the great shock from biting, and prevented the breakage of tooth in dinosaurs.

In the current study, the researchers compared microscopic tooth structure of non-avian dinosaurs, including Troodon, Anchiornis, and Microraptor, with Cretaceous toothed bird representatives, like Sapeornis and Jeholornis.

The results showed that even though all the sampled Mesozoic bird teeth retained the simplified enamel, the porous mantle dentine layer between the enamel and the true dentin were all lost. Surprisingly, one tooth from a new Microraptor fossil also lost this layer as well.

The team proposed that feeding strategies for Mesozoic toothed birds were remarkably contrasted with that of their competitors, the predatory dinosaurs. The teeth of fossil birds were no longer used for biting or tearing, and no longer needed that extra dentine layer to provide special mechanical protection.

The results provided indirect evidence supporting that birds and a few theropod dinosaurs shifted their dietary preferences. They avoided direct ecological competition for food resources with carnivorous dinosaurs.

Compared to the prevailing trend (i.e. becoming

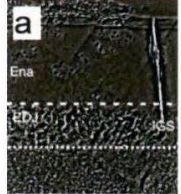

Troodontid

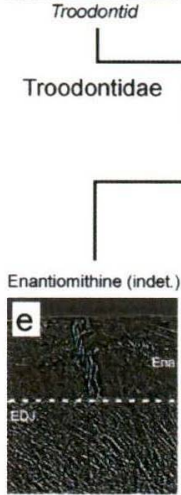

TXM imaging showing the microscopic tooth features in non-avian dinosaurs and bird species sampled in the new study. IGS represents the porous mantle dentin beneath the enamel in carnivorous dinosaurs, absent in birds.

herbivorous, insectivorous, and omnivorous) that these early birds had, only a few other dinosaurs have convergently evolved the same habit that the new Microraptor showed. 